\title{
Article
}

\section{Correlation between processing parameters and mechanical properties as a function of substrate polarisation and depth in a nitrided 316 L stainless steel using nanoindentation and scanning force microscopy}

\author{
Randall, N.X., Renevier, Nathalie, Michel, H and Collignon, P \\ Available at http://clok.uclan.ac.uk/11610/ \\ Randall, N.X., Renevier, Nathalie ORCID: 0000-0003-2471-7236, Michel, H and \\ Collignon, $P$ (1997) Correlation between processing parameters and \\ mechanical properties as a function of substrate polarisation and depth in a \\ nitrided 316 L stainless steel using nanoindentation and scanning force \\ microscopy. Vacuum, 48 (10). pp. 849-855. ISSN 0042-207X
}

It is advisable to refer to the publisher's version if you intend to cite from the work. http://dx.doi.org/10.1016/50042-207x(97)00084-5

For more information about UCLan's research in this area go to http://www.uclan.ac.uk/researchgroups/ and search for < name of research Group>.

For information about Research generally at UCLan please go to http://www.uclan.ac.uk/research/

All outputs in CLoK are protected by Intellectual Property Rights law, including Copyright law. Copyright, IPR and Moral Rights for the works on this site are retained by the individual authors and/or other copyright owners. Terms and conditions for use of this material are defined in the policies page. 


\section{Correlation between processing parameters and mechanical properties as a function of substrate polarisation and depth in a nitrided $316 \mathrm{~L}$ stainless steel using nanoindentation and scanning force microscopy}

N X Randall, ${ }^{a}$ N Renevier, ${ }^{b} \mathrm{H}$ Michel' and P Collignon, ${ }^{d a}$ CSEM Instruments, Jacquet-Droz 1, CH-2007 Neuchâtel, Switzerland; ${ }^{b}$ Balzers S. A., Z. A., Rue J. Monnet, 68390 Sausheim, France; ' Laboratoire de Science et Génie des Surfaces (URA CNRS 1402), Ecole des Mines, Parc de Saurupt, 54042 Nancy, France, 'Balzers S. A., Parc d'activités de l'Esplanade, 77462 St Thibault des Vignes, France

received 7 April 1997

The effects of substrate polarisation in a nitrided $316 \mathrm{~L}$ stainless steel have been investigated in an attempt to accurately correlate processing parameters with surface mechanical properties. Nanoindentation allows the Vickers hardness to be measured at precise depths, meaning that the variation in properties with nitriding depth can be evaluated and correlated with the process parameters. By combining such measurements with surface imaging techniques (scanning force microscopy and scanning electron microscopy) and electron probe micro-analysis, it is possible to explain both the mechanical property and microstructural variations of such layers, having been produced in a low pressure arc plasma discharge at $680 \mathrm{~K}$ with a mixed Ar- $\mathrm{N}_{2}$ gas.

In this study the nanoindentation technique is presented as a new and valid method for the characterisation of nitrided layers, shown by hardness measurements on four nitrided layers produced with different substrate polarisation potentials. The net advantages of such an approach over conventional methods (e.g.

microhardness testing) and the possibility of analysing microstructural phases previously not well detected by $X$-ray diffraction, make nanoindentation an attractive tool for a more complete understanding of the nitriding process. (C) 1997 Elsevier Science Ltd. All rights reserved

\section{Introduction}

Low pressure thermionic are nitriding ${ }^{1,2}$ has shown that nitrogen reactivity can be very high in such a process, making it interesting to evaluate its efficiency on austenitic stainless steels. It is known that a nitriding treatment improves the tribological properties of stainless steels without affecting their corrosion behaviour, provided that it is performed below $720-770 \mathrm{~K}^{3.4}$ Below such temperatures there is no $\mathrm{CrN}$ precipitation within the diffusion layers; only a metastable f.c.c. phase $\left(\gamma_{N}\right)$ containing a high concentration of nitrogen in solid solution is formed. This supersaturated f.c.c. structure, sometimes described as expanded austenite, can be obtained by different processes, ${ }^{5-7}$ but of greater interest is an $\mathrm{MN}$-like $\mathrm{CrN}$ phase which recent studies have shown to exist in the near surface region of the diffusion layer, depending on the process parameters. ${ }^{8}$ The kinetics of the precipitation of this phase are still not well known.

Therefore, an additional characterisation method is required in order to distinguish such a phase from the more common $\gamma_{\mathrm{N}}$ f.c.c. phase. In assuming that this phase may be present as a function of depth in a nitrided layer leads to the possibility of using a depth-sensitive indentation method which is capable of measuring hardness at very small depths and with high accuracy.

In recent years, nanoindentation has become widely accepted as the logical solution to microindentation, the latter being limited by the resolution of an optical microscope, as this is used to determine the imprint diagonal and thus the hardness of the tested material. The nanoindentation principle relies on the continuous measurement of force and displacement as an indenter, of known geometry, is pressed into a sample material. ${ }^{914}$ The force is usually applied via an electromagnet, in which case the current in the coil determines the load, or by a piezoelectric load cell where the inherent inaccuracies in such a system are corrected by interferometry. The displacement is measured, in most cases, by a capacitive sensor. With instruments now having microNewton force and nanometer depth resolutions, it is possible to 


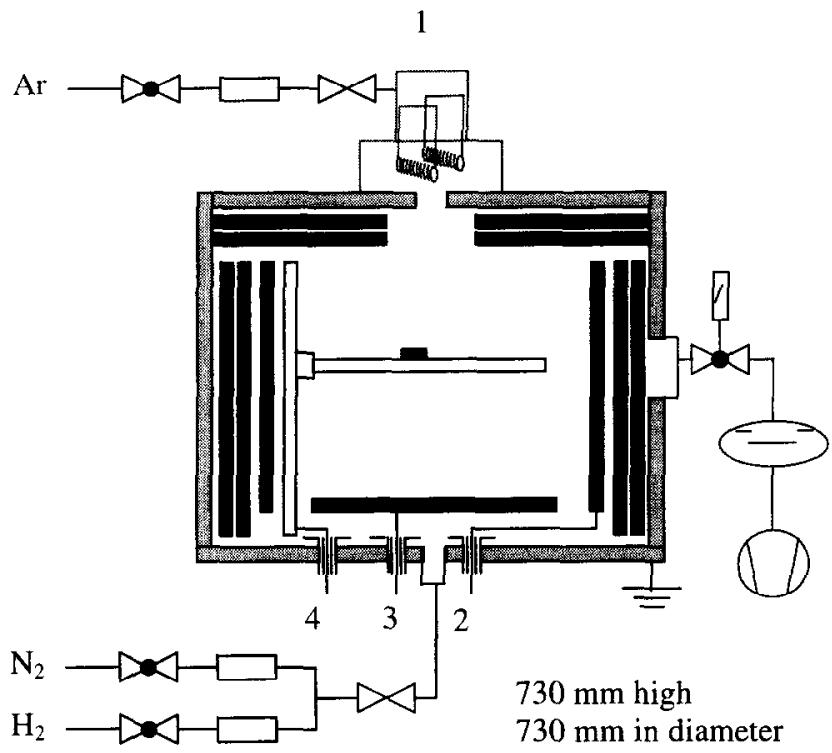

Figure 1. Schematic representation of the main components of the low pressure arc discharge nitriding chamber, comprising: plasma beam source (1); cylindrical (2) and flat (3) anodes; and heating substrate holder (4).

produce load-displacement curves representative of the material response in terms of hardness, modulus and elastic recovery. ${ }^{15}$

Having established the motivation for the present work, a selection of nitrided layers produced with different substrate polarisation potentials are characterised using the aforementioned nanoindentation technique, and the results explained using high resolution scanning force microscopy (SFM), scanning electron microscopy (SEM), electron probe micro-analysis (EPMA), secondary neutral mass spectroscopy (SNMS) and Xray diffraction $(X R D)$.

A clear correlation was found between the nanohardness of the nitrided layers and their polarisation potentials, and in addition, the presence of the MN-like $\operatorname{CrN}$ phase at the outer surface was confirmed.

\section{Experimental set-up}

Nitriding device. The expcrimental apparatus used for all nitriding treatments, a Balzers BAI730N, is shown in Figure 1. A high current, low voltage thermionic arc is generated in argon in an ionisation chamber ( 1 in Figure 1) mounted on the top of the nitriding reactor. Segmented anodes (2-3 in Figure 1) which are distributed within the reactor spread the plasma throughout the whole processing chamber, thus creating a uniform low pressure plasma $(0.4-0.8 \mathrm{~Pa})$. With an appropriate aperture between the ionisation chamber and the reactor, an intense glow discharge supported by a low voltage $(25-40 \mathrm{~V})$, high current (120 A on each anode) thermionic arc is created.

A heating resistance (4 in Figure 1) is used to provide a uniform temperature $(680 \mathrm{~K})$. Prior to nitriding, a 90 min cleaning treatment is performed in an $\mathrm{Ar}-25 \% \mathrm{H}_{2}$ gas mixture (corresponding to $0.5 \mathrm{~Pa}$ total pressure) in order to remove the surface oxide layer. The four AISI $316 \mathrm{~L}$ samples to be compared in this study were nitrided for $6 \mathrm{~h}$ at $680 \mathrm{~K}$ in an $\mathrm{Ar}-66 \mathrm{~N}_{2} \%$ gas mixture with different polarisation potentials, as listed in Table 1.

Nanoindentation. The instrument used for nanoindentation was a CSEM Nano Hardness Tester (NHT), comprising two distinct components, a measuring head for performing indentations and an optical microscope for selecting a specific sample site prior to indentation and for checking the location of the imprint after indentation. Both components are directly linked by an electromechanical positioning system which allows movement in two perpendicular horizontal axes with a lateral displacement resolution of $1 \mu \mathrm{m}$. This instrument is a development of an earlier ultramicrohardness tester ${ }^{16}$ which is based on existing technology ${ }^{17}$ and its principle is described elsewhere. ${ }^{18}$ The main advantage of this instrument is its differential measurement of the sample surface, made possible by a sapphire reference ring which remains in contact with the sample during the loading/unloading cycle, giving exact positioning of the Vickers indenter tip relative to the sample surfacc. Thus the clasticity of the sample and holder is compensated, as is thermal drift during measurement.

Indentations were performed at depths of 100, 200, 300, 400, $500,750,1000,1250,1500$ and $1750 \mathrm{~nm}$ on all samples in order to evaluate the evolution of hardness with depth into the nitrided layer. Deeper penetration depths were not used, so as to prevent inaccuracies due to substrate effects. The loading rate was kept constant for all measurements, and five indentations were made at each depth.

Surface characterisation SFM was carricd out using a CSEM Atomic Scale Tribometer, ${ }^{19.21}$ a stand-alone instrument having sub-nanometer lateral and vertical displacement resolution. Topographical images were made at scan sizes of 20 and $5 \mu \mathrm{m}$,

Table 1. Experimental conditions for the four chosen samples

\begin{tabular}{|c|c|c|c|c|}
\hline & Experiment 1 & Experiment 2 & Experiment 3 & Experiment 4 \\
\hline \multicolumn{5}{|l|}{ Precleaning } \\
\hline Time(h) & 1.5 & 1.5 & 1.5 & 1.5 \\
\hline Polarisation(V) & -50 & -20 & 0 & +20 \\
\hline Gas composition & $\mathrm{Ar}-25 \% \mathrm{H}_{2}$ & $\mathrm{Ar}-25 \% \mathrm{H}_{2}$ & $\mathrm{Ar}-25 \% \mathrm{H}_{2}$ & $\mathrm{Ar}-25 \% \mathrm{H}_{2}$ \\
\hline \multicolumn{5}{|l|}{ Nitriding } \\
\hline Time (h) & 6 & 6 & 6 & 6 \\
\hline Temperature $(\mathbf{K})$ & 680 & 680 & 680 & 680 \\
\hline Polarisation (V) & -50 & -20 & 0 & +20 \\
\hline Gas composition & $\begin{array}{l}\text { Ar }-66 \% \mathrm{~N}_{2} \\
\text { (at } 0.8 \mathrm{~Pa} \text { total pressure) }\end{array}$ & $\begin{array}{l}\text { Ar }-66 \% \mathrm{~N}_{2} \\
\text { (at } 0.8 \mathrm{~Pa} \text { total pressure) }\end{array}$ & $\begin{array}{l}\mathrm{Ar}-66 \% \mathrm{~N}_{2} \\
\text { (at } 0.8 \mathrm{~Pa} \text { total pressure) }\end{array}$ & $\begin{array}{l}\mathrm{Ar}-66 \% \mathrm{~N}_{2} \\
\text { (at } 0.8 \mathrm{~Pa} \text { total pressure) }\end{array}$ \\
\hline $\mathrm{N}$ concentration at the surface (at $\%$ ) & 26.9 & 30.8 & 26.9 & 34.5 \\
\hline Layer thickness $(\mu \mathrm{m})$ & $7 \pm 1$ & $8 \pm 2$ & $7 \pm 1$ & $8 \pm 2$ \\
\hline
\end{tabular}


the former to compare height variations between different grains, the latter in order to look at the grain morphology with high resolution and to investigate any correlation between polarisation potential and surface grain structure.

Optical microscopy was used to evaluate the thickness of each nitrided layer by cutting and polishing a representative section. SEM was used to gain an overview of the grain structure and the dispersion of differing grain types. EPMA and SNMS allowed the surface nitrogen concentration to be quantified and XRD was used to determine the phases present and their orientation.

\section{Results and Discussion}

The nitrided layers obtained, having all been subjected to crystallographic compression and spatially anisotropic constraints near the surface, are discussed in terms of their chemical composition. Figure 2 shows a typical glancing angle XRD pattern obtained with an incidence angle of $4^{\circ}$ for different nitriding substrate polarisations $(-50 \mathrm{~V},-20 \mathrm{~V}$, floating potential, $+20 \mathrm{~V})$ and the following are observed:

- The f.c.c. base matrix, $\gamma$, having a lattice parameter equal to $0.359 \mathrm{~nm}$, was not visible with an incidence angle of $4^{\circ}$ and the diffusion layers had thickness $7-10 \mu \mathrm{m}$.

- An expanded austenitc phase, consisting of an f.c.c. solid solution, $\gamma_{N}$, of lattice parameter between 0.377 and $0.379 \mathrm{~nm}$ is observed on all samples and measured along the (111) $\gamma_{N}$ plane. A supersaturated austenite phase is also observed, consisting of a f.c.c. solid solution, $\gamma_{N}^{s}$, which has a higher nitrogen concentration than the expanded austenite phase. This supersaturated phase is only evident for samples 2 and 4 , the lattice parameter being measured between 0.387 and $0.389 \mathrm{~nm}$ along the (111) $\gamma_{N}^{S}$ plane. In addition, it can be seen that the expanded austenite peaks are large, this being due to the presence of stacking faults and other defects, high internal stresses and the concentration gradient between each layer. Such phenomena have already been observed by Saker et al. after PVD treatment. $^{22}$

- A phase of partially crystallised MN-like $\mathrm{CrN}$ is seen, this having a lattice parameter between 0.416 and $0.412 \mathrm{~nm}$ as measured along the (111) MN plane. This confirms that precipitation of the MN-like phase has occurred by partial decomposition of the $\gamma_{N}^{S}$ or $\gamma_{N}$ phases.

Figure 3 shows a cross-sectional SEM micrograph of the diffusion layers of the nitrided AISI $316 \mathrm{~L}$ steel sample biased at $-20 \mathrm{~V}$. A similar surface structure was observed for all four sample types, this suggesting that regardless of sample polarisation, a partial transformation of $\gamma_{N}^{S}$ or $\gamma_{N}$ occurs after $6 \mathrm{~h}$ treatment at $680 \mathrm{~K}$. Secondary electron analysis confirmed the presence of a surface layer having a composition different to that of the saturated austenite phase $\left(\gamma_{N}\right)$ beneath it. This $\mathrm{MN}$-like $\mathrm{CrN}$ phase showed a certain fragility near the interface, with ripping of material occurring as a result of polishing. The layer thickness measured between 300 and $600 \mathrm{~nm}$. The $\gamma_{N}$ phase had a thickness of approximately $6 \mu \mathrm{m}$ with stacking faults and twinning planes being clearly visible. The substrate matrix $(\gamma)$ can be seen below the $\gamma_{N}$ phase.

Such a modified surface layer had a nitrogen concentration, as measured by EPMA, of between 27 at \% (samples 1 and 3) and 35 at $\%$ (samples 2 and 4) (Table 1). A correlation could be found between the XRD and the EPMA measurements.

The SEM micrograph in Figure 4 shows the different types of

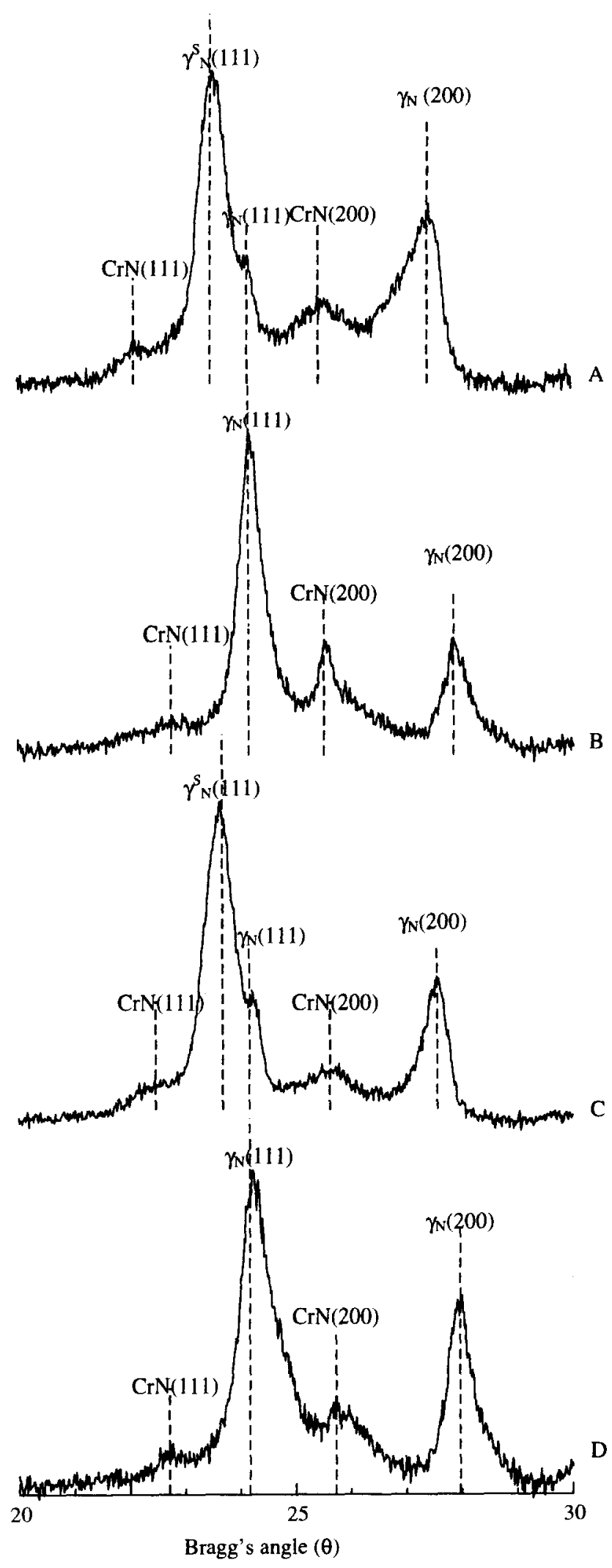

Figure 2. AISI $316 \mathrm{~L}$ steel sample nitrided in $\mathrm{Ar}-66 \% \mathrm{~N}_{2}$ at $683 \mathrm{~K}$ during $6 \mathrm{~h}$ at $0.8 \mathrm{~Pa}$ and $120 \mathrm{~A}$ on each anode, with sample polarisation $+20 \mathrm{~V}$ (A), floating potential (B), $-20 \mathrm{~V}(\mathrm{C}),-50 \mathrm{~V}$ (D). The XRD pattern was taken at the outer surface of the sample $\left(\lambda K_{\mathrm{x}} \mathrm{Co}=0.1 .7889 \mathrm{~nm}\right)$. 


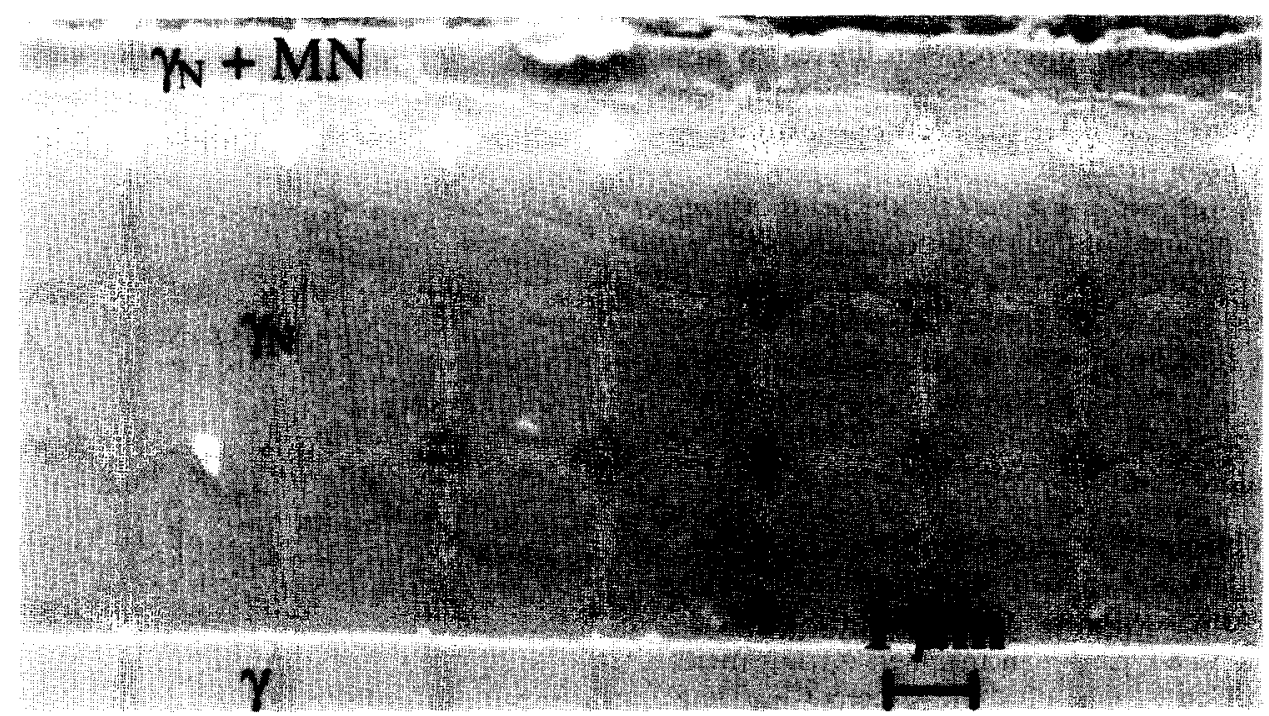

Figure 3. Cross-sectional SEM micrograph of diffusion layers for an AISI $316 \mathrm{~L}$ steel sample nitrided in Ar- $60 \% \mathrm{~N}_{2}$ during $6 \mathrm{~h}$ at $680 \mathrm{~K}$ and a $0.8 \mathrm{~Pa}$ and $120 \Lambda$ on each anode at a polarisation of $-20 \mathrm{~V}$. The structure is revealed by Parmitter's etching reagent.

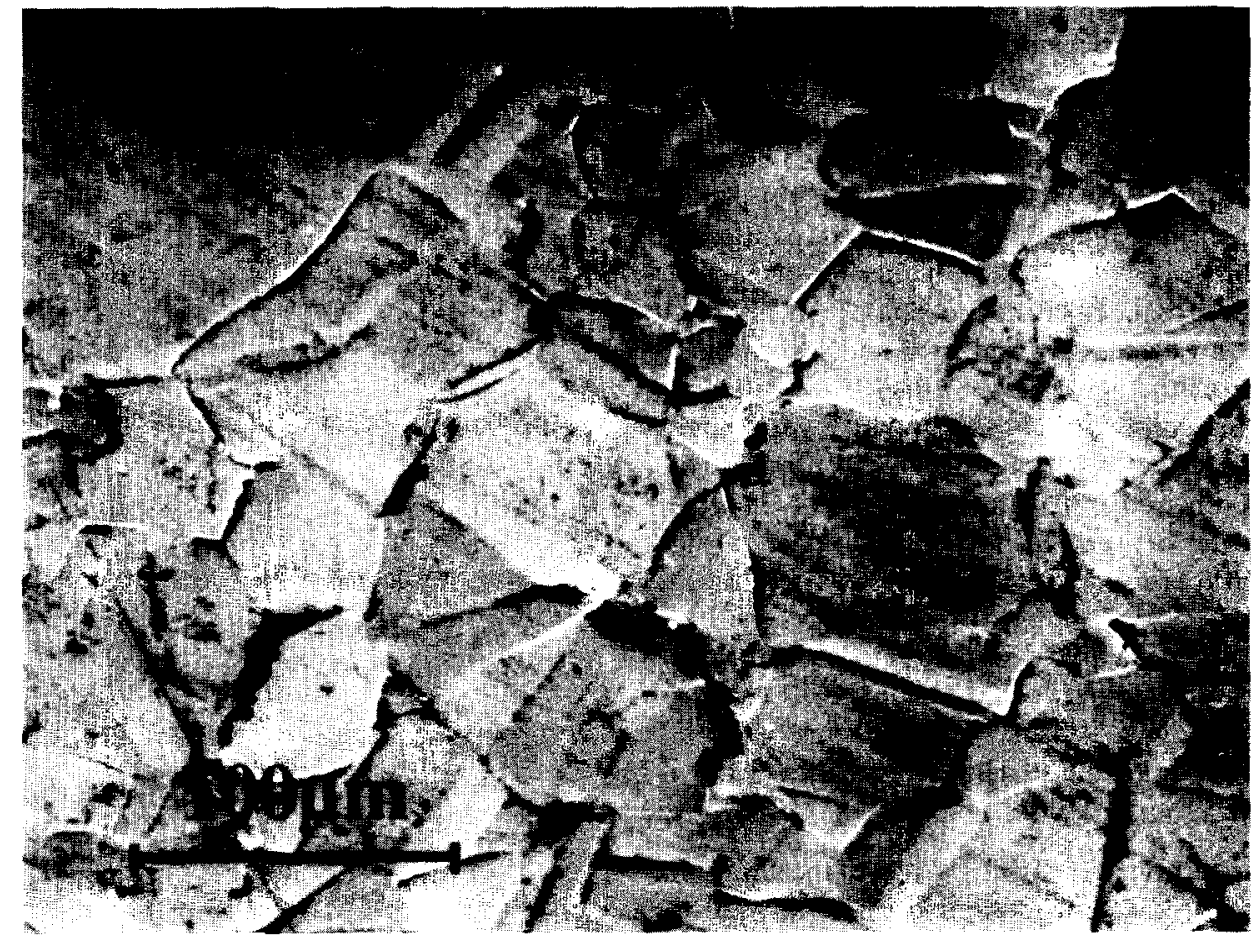

Figure 4. SEM micrograph of surface grain structure (nitriding conditions as in Figure 3).

grain present and their size variation. The grain boundaries seemed to have height differences which were particularly apparent but difficult to quantify using this method. Hence, a series of SFM images were made in order to investigate such differences, as can be seen in Figure 5 a which shows the boundaries between three grains and the cliff-like nature of one such interface. The diffusion layer is subjected to intense compressive strains and the dislocation densities created (in particular stacking faults and twinning planes) are much higher than in the substrate material. Previous work ${ }^{23}$ has shown that surface height variation is a good indicator of the degree of modification occurring on the surface of such stainless steels. The height of the cliff shown is in the order of $200 \mathrm{~nm}$, this being due to the high surface nitrogen concentration together with the negative polarisation potential used. The SFM images on all samples confirmed that the height variation becomes more pronounced with greater negative polarisation potentials.

Figure 6 shows the variation of Vickers hardness with penetration depth. Such nanoindentation profiles confirmed a net variation in hardness across the first $1750 \mathrm{~nm}$ of the $8-10 \mu \mathrm{m}$ thick nitrided layers. Such a variation corresponds with results obtained in a study of nitriding growth rates ${ }^{24}$ in which different diffusion regimes evolve with time. During the first hour the diffusion layer grows in the form of a $\gamma_{N}$ solid solution followed by apparition of the aforementioned cliff-like interfaces. Therefore the change of slope associated with a diffusion transition can explain the formation of new phases within the nitrided layer.

Two separate regions can be distinguished as a function of 

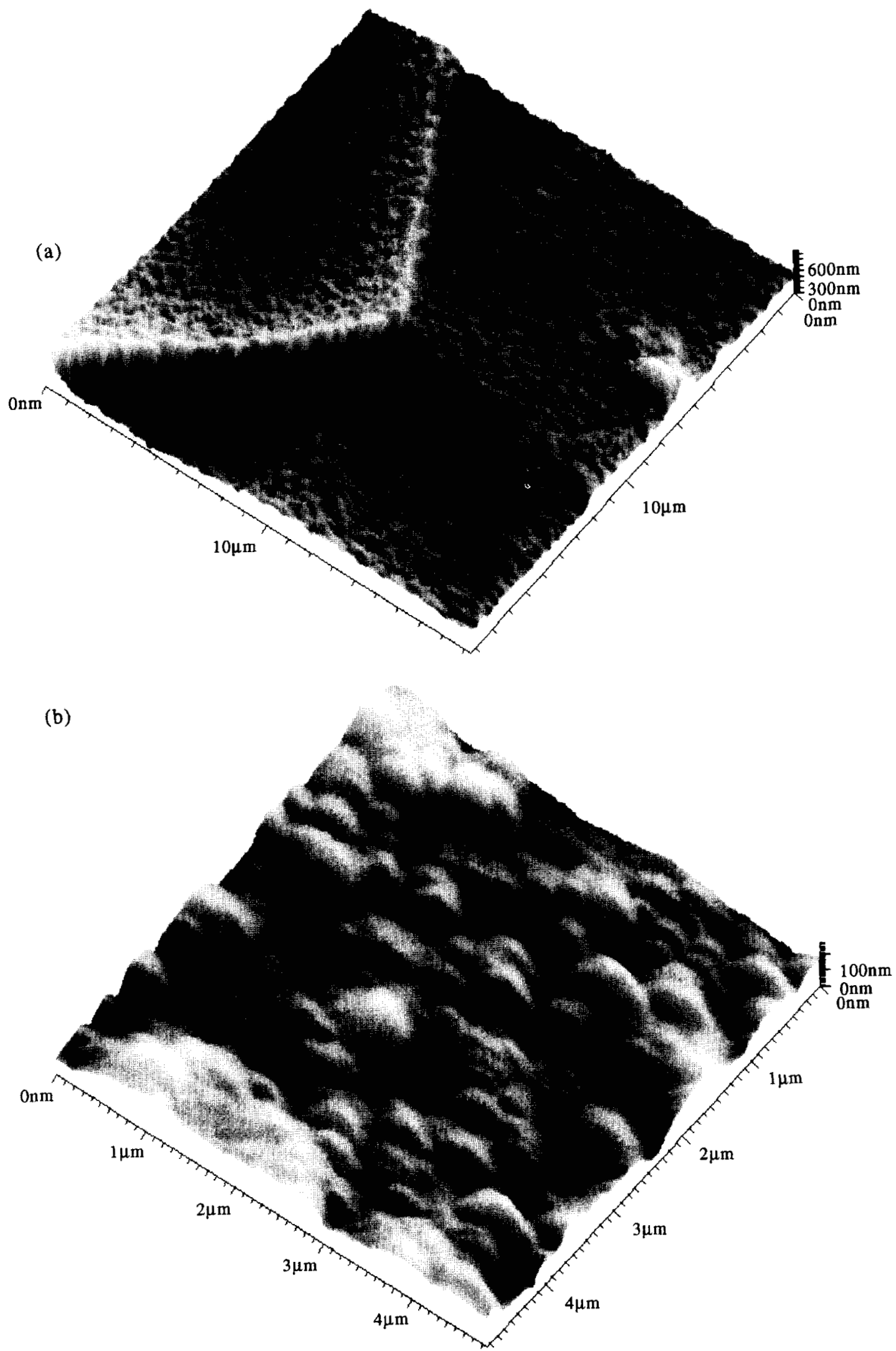

Figure 5. Three-dimensional SFM images of nitrided surface topography (sample polarisation $=-20 \mathrm{~V}$ ): (a) grain boundaries between three grains; and (b) high resolution image of typical grain structure. 


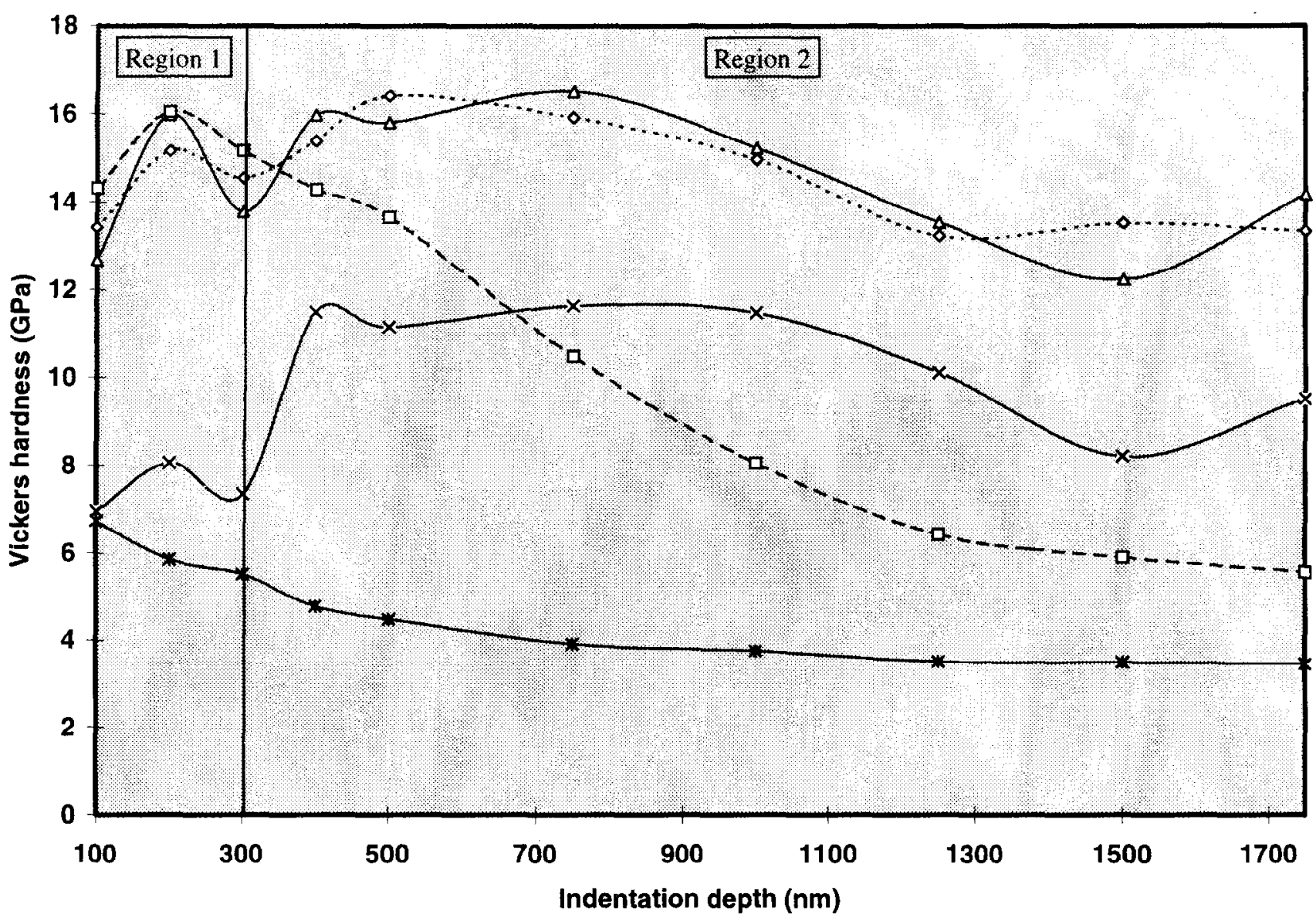

Figure 6. Variation of nanohardness with depth below surface for the four samples nitrided at different polarisation potentials and the virgin AISI $316 \mathrm{~L}$ substrate: $(\diamond)+20 \mathrm{~V} ;(\mathrm{x}) 0 \mathrm{~V} ;(\triangle)-20 \mathrm{~V} ;(\square)-50 \mathrm{~V}$; and $\left({ }^{*}\right) 316 \mathrm{~L}$ substrate.

penetration depth, $d_{I}$; In the first region $\left(d_{I}<300 \mathrm{~nm}\right)$, the presence of a different phase ( $\mathrm{MN}$-like $\mathrm{CrN}$ ) is confirmed by a sharp transition in hardness. This phase, created during the nitriding process and previously observed by Saker et al. after a $60 \mathrm{~h}$ treatment at $620 \mathrm{~K},{ }^{22}$ can be attributed to the decomposition of the $\gamma_{N}$ phase during treatment. In the second region $\left(d_{i}>300 \mathrm{~nm}\right)$, the hardness gradually decreases as reported previously ${ }^{25}$ with sample $1(-50 \mathrm{~V})$ decreasing more strongly than the others due to its lower nitrogen concentration at the surface caused by more efficient electron bombardment during nitriding. Samples 2 and $4(-20$ and $+20 \mathrm{~V}$ respectively) seem to have almost identical hardness profiles, this corresponding to their similar nitrogen concentrations. Sample $3(0 \mathrm{~V})$ has a profile of the same form as that of sample 2 except that its measured hardness is approximately $30 \%$ less. This can be explained by weaker electronic bombardment of the surface which in turn makes the development of internal strains less favourable leading to a reduced hardness of the nitrided layer. This is confirmed by this samples' lower surface nitrogen concentration.

It is now widely accepted that hardness measurements are sensitive to the properties of layers underneath the indenter lying within 10 times the indentation depth. For the measured layers having thicknesses of $\sim 10 \mu \mathrm{m}$ this means that any indentation depth exceeding $\sim 1 \mu \mathrm{m}$ will he subject to substrate effects owing to the elastic/plastic deformation field around the indentation being deeper than the nitrided layer. Evidence of such a phenom- enon is visible for samples 2, 3 and 4, whose hardness profiles decrease gradually but then increase at depths greater than $1.5 \mu \mathrm{m}$. Therefore, hardness values truly representative of the nitrided layer are only possible if the indentation depth remains less than this value.

Regarding the nanoindentation profile of the AISI $316 \mathrm{I}$, substrate, it was apparent that the measured Vickers hardness increases as the indentation depth decreases. At depths greater than about $700 \mathrm{~nm}$ the hardness value stabilised to around 3.8 GPa, this correlating well with values obtained by conventional microindentation. The relatively sharp increase in hardness over the first $500 \mathrm{~nm}$ was attributed to a mixture of mechanical and chemical surface artefacts. The former relates to the mechanical polishing of the surface prior to nanoindentation (in this case down to a finish of $0.25 \mu \mathrm{m}$ using alumina paste) which is known to induce a plastically deformed layer on the surface which is significantly harder than the base material. The latter refers to the oxide and other chemical films that inevitably form on normal experimental surfaces, even if only as a result of atmospheric oxidation. Previous work ${ }^{26}$ has shown that the presence of an oxide film only $5 \mathrm{~nm}$ thick can drastically increase the hardness value obtained when the indentation depth is small enough. The roughness of an indented surface can also contribute to error in the measurement of hardness when such a roughness is of the same order as the indentation depth. However, the SFM imaging of all measured surfaces prior to indentation determined 
the surface roughness as being in the range $10-20 \mathrm{~nm}$, which, for penetration depths exceeding $100 \mathrm{~nm}$, could be considered as negligible.

\section{Conclusions}

This study has shown that significant variation in mechanical properties is possible in nitrided austenitic stainless steels as a function of substrate biasing. Nanoindentation has been demonstrated as a valid analytical technique for the accurate characterisation of surface nitrided layers, and in this case for the confirmation of a distinct $\mathrm{MN}$-like $\mathrm{CrN}$ phase, present only within the first $300 \mathrm{~nm}$ of the layer, which was not casily detectable by XRD. A correlation has been established between the hardness profiles and the surface nitrogen concentration. SFM has revealed the variation in surface grain structure depending on substrate polarisation, and an increase in grain boundary height has been correlated to greater negative polarisation potentials. This study has allowed a more complete characterisation of phenomena occurring in the surface and near-surface regions of nitrided stainless steel.

\section{References}

1. Renevier, N., Michel, H., Collignon, P. and Czerwiec, T., Surf. Coat. Tech., 1996, 8687, 285.

2. Renevier, N., Michel, H., Collignon, P. and Czerwiec, T., Surf. Coat. Tech., 1997, 95, 1-3.

3. Menthe, E., Rie, K. T., Schultze, J. W. and Simson, S., Surf. Coat. Tech., 1995, 74-75, 131.

4. Zhang, Z. L. and Bell, T., Surf. Eng., 1995, 1, 131

5. Lei, M. K. and Zhang, L. L., J. Vac. Sci. Tech. A, 1995, 13, 2986.
6. Cordier-Robert, C., Bourdeau, L. and Magnin, T., Foct, L., Mat. Lett., 1994, 20, 113.

7. Collins, G. A., Hutchings, R., Short, K. T., Tendys, J. and Li, X., Samandi, M., Surf. Coat. Tech., 1995, 74, 417.

8. Bourjot, A. and Foos, M.. Frantz, C., Plasma Surface Engineering. $1989,2,777-784$

9. Pethica, J. B., Hutchings, R. and Oliver, W. C., Philos. Mag. A, 1983, 48, 593-606.

10. Loubet, J., Georges, I. M., Marchesini, D. and Meille, G., J. Tribology, 1984, 106, 43-48.

11. Page, T. F., Oliver, W. C. and McLlargue, C. J., J. Mater. Res., 1992, $7(3), 00$.

12. Bhushan, B., Williams, V. S. and Shack, R. V., Trans. ASME J. Tribol., 1988, 110, 563-571.

13. Nishibori, M. and Kinosita, K., Thin Solid Films, 1978, 48, 325-331.

14. Pollock, H. M., ASM Handbook, Vol. 18. ASM International, Ohio, 1992, pp. 419-429.

15. Oliver, W. C., Vol 11, MRS Bulletin, 1986, Oct, 15-19.

16. Hintermann, H. E., Fresenius J. Anal Chem., 1993, 346, 45-52

17. Oliver, W. C. and Pharr, G. M., J. Mater. Res., 1992, 7(6), 1564 1583.

18. Randall, N. X., Julia-Schmutz, C., Soro, J. M., Von Stebut, J. and Zacharie, G., Thin Solid Films, 1997, in press.

19. Binggeli, M., Christoph, R., Hintermann, H. and Marti, O., Surface and Coatings Tech., 1993, 62, 523-528.

20. Randall, N. X., in Tribology -Solving Friction and Wear Problems, ed. Wilfried $J$ Bartz. Tribology Proceedings of the 10 th International Colloquium, Vol. 3. 1996, pp. 1885-1890.

21. Randall, N. X., Christoph, R., Droz, S. and Julia-Schmutz, C., Thin Solid Films, 1996, 291, 348-354

22. Saker, A., Leroy, C., Michel, H. and Frantz, C., Mat. Sci. Engi. A, 1991, 140, 702 .

23. Samandi, M., Shedden, B. A., Smith, D. I., Collins, G. A., Hutchings, R. and Tendys, J., Surf. Coat. Tech., 1993, 59, 261.

24. N. Renevier, H. Michel, P. Collignon and T. Czerwiec, Surf. Cont. Tech., 1997, in press.

25. Hannula, S. P., Nenonen, P. and Hirvonen, J. P., Thin Solid Films, $1989,181,343-350$.

26. Pethica, J. B. and Tabor, D., Surface Science, 19/9, 89, 182-190. 